Research

\title{
Complement activation in Ghanaian children with severe Plasmodium falciparum malaria
}

Gideon K Helegbe 1,4,6, Bamenla Q Goka², Joergen AL Kurtzhals³, Michael M Addae ${ }^{4}$, Edwin Ollaga ${ }^{5}$, John KA Tetteh4 ${ }^{4}$ Daniel Dodoo ${ }^{4}$, Michael F Ofori ${ }^{4}$, George Obeng-Adjei ${ }^{2}$, Kenji Hirayama ${ }^{6}$, Gordon A Awandare ${ }^{7}$ and Bartholomew D Akanmori*4

\begin{abstract}
Address: ${ }^{1}$ Department of Biochemistry and Molecular Medicine, SMHS, UDS, Tamale, Ghana, ${ }^{2}$ Department of Child Health, Korle-Bu Teaching Hospital, Accra, Ghana, ${ }^{3}$ Centre for Medical Parasitology, Department of Clinical Microbiology, Copenhagen University Hospital (Righospitalet), Copenhagen, Denmark, ${ }^{4}$ Immunology Dept., NMIMR, College of Health Sciences, University of Ghana, Legon, Ghana, ${ }^{5}$ Blood Bank, Korle-Bu Teaching Hospital, Accra, Ghana, ${ }^{6}$ Department of Immunogenetics, Institute of Tropical Medicine (NEKKEN), Nagasaki University, Japan and ${ }^{7}$ Biochemistry Department, University of Ghana, Legon, Ghana, and Division of Military Casualty Research, Department of Cellular Injury, Walter Reed Army Institute of Research, Silver Spring, MD, Ghana

Email: Gideon K Helegbe - kofigidi@yahoo.com; Bamenla Q Goka - bamenla@yahoo.co.uk; Joergen AL Kurtzhals - joergen.kurtzhals@rh.regionh.dk; Michael M Addae - maddae@excite.com; Edwin Ollaga - maddae@excite.com; John KA Tetteh - jtetteh@noguchi.mimcom.net; Daniel Dodoo - ddodoo@noguchi.mimcom.net;

Michael F Ofori - mofori@noguchi.mimcom.net; George Obeng-Adjei - goadjei@yahoo.com; Kenji Hirayama - hiraken@nagasaki-u.ac.jp; Gordon A Awandare - gordon.awandare@us.army.mil; Bartholomew D Akanmori* - bakanmori@ noguchi.mimcom.net

* Corresponding author
\end{abstract}

Published: 17 December 2007

Malaria Journal 2007, 6:165 doi:10.1186/1475-2875-6-165
Received: II July 2007

Accepted: 17 December 2007

This article is available from: http://www.malariajournal.com/content/6/1/165

(c) 2007 Helegbe et al; licensee BioMed Central Ltd.

This is an Open Access article distributed under the terms of the Creative Commons Attribution License (http://creativecommons.org/licenses/by/2.0), which permits unrestricted use, distribution, and reproduction in any medium, provided the original work is properly cited.

\begin{abstract}
Background: Severe anaemia (SA), intravascular haemolysis (IVH) and respiratory distress (RD) are severe forms of Plasmodium falciparum malaria, with RD reported to be of prognostic importance in African children with malarial anaemia. Complement factors have been implicated in the mechanism leading to excess anaemia in acute $P$. falciparum infection.

Methods: The direct Coombs test (DCT) and flow cytometry were used to investigate the mean levels of RBC-bound complement fragments $(\mathrm{C} 3 \mathrm{~d}$ and $\mathrm{C} 3 \mathrm{~b} \alpha \beta)$ and the regulatory proteins [complement receptor I (CD35) and decay accelerating factor (CD55)] in children with discrete clinical forms of $P$. falciparum malaria. The relationship between the findings and clinical parameters including coma, haemoglobin $(\mathrm{Hb})$ levels and RD were investigated.

Results: Of the 484 samples tested, I I I (27\%) were positive in DCT, out of which II5/I3I (87.8\%) were positive for $\mathrm{C} 3 \mathrm{~d}$ alone while $16 / \mathrm{I} 3 \mathrm{I}$ ( $12.2 \%$ ) were positive for either IgG alone or both. $67.4 \%$ of the study population were below 5 years of age and DCT positivity was more common in this age group relative to children who were 5 years or older (Odds ratio, $O R=3.8 ; 95 \% \mathrm{Cl}, 2.2-6.7$, $\mathrm{P}<0.00 \mathrm{I})$. DCT correlated significantly with $\mathrm{RD}(\beta=-304, \mathrm{p}=0.006)$, but multiple regression analysis revealed that, $\mathrm{Hb}(\beta=-0.34 \mathrm{I}, \mathrm{p}=0.0 \mathrm{I} 2)$ and coma $(\beta=-0.256, \mathrm{p}=0.034)$ were stronger predictors of RD than DCT $(\beta=0.228, p=0.061)$. DCT was also not associated with IVH, $p=$ 0.19 , while spleen size was inversely correlated with $\mathrm{Hb}(r=-402, \mathrm{p}=0.00 \mathrm{I})$. Flow cytometry showed similar mean fluorescent intensity (MFI) values of CD35, CD55 and C3b $\alpha \beta$ levels on the
\end{abstract}


surfaces of RBC in patients and asymptomatic controls (AC). However, binding of $C 3 b \alpha \beta$ correlated significantly with CD35 or CD55 ( $<<0.001)$.

Conclusion: These results suggest that complement activation contributed to anaemia in acute childhood $P$. falciparum malaria, possibly through induction of erythrophagocytosis and haemolysis. In contrast to other studies, this study did not find association between levels of the complement regulatory proteins, CD35 and CD55 and malarial anaemia. These findings suggest that complement activation could also be involved in the pathogenesis of RD but larger studies are needed to confirm this finding.

\section{Background}

The mortality associated with malaria largely occurs in children as a result of complications, such as severe anaemia (SA), intravascular haemolysis (IVH), cerebral malaria (CM) and metabolic acidosis, clinically manifested as respiratory distress (RD) [1-5]. Sub-Saharan Africa accounts for $90 \%$ of the world's 300-500 million malaria cases and 1.5-2.7 million deaths annually [6]. A recent study has shown that in Ghana, the most common manifestations of severe malaria (SM) are SA (36.5\%), followed by RD (24.4\%) and CM (5.4\%) [7]. There are no reports of the relative contribution of IVH to SM cases in Ghana.

IVH due to $P$. falciparum is a condition with high casefatality if diagnosis and treatment are not optimal [8]. It is usually considered a rare complication of malaria in endemic areas, but recent studies have highlighted its importance $[5,9]$. Although it appears that the direct RBC destruction due to IVH is a minor contributor to malarial anaemia it is nonetheless strongly associated with erythrophagocytosis and with a poor prognosis [5,9]. Most studies of IVH in malaria have focussed on the influence of glucose 6-phosphate dehydrogenase (G6PD) [10-12], and the role played by antimalarial drugs such as chloroquine $[13,14]$. Mechanical trauma from a damaged endothelium, complement fixation and activation on the RBC surface, and infectious agents may cause direct membrane degradation and cell destruction [4].

It has been observed that the degree of red blood cell (RBC) breakdown during acute malaria cannot be explained solely by the direct destruction of RBC by malaria parasite schizogony [15]. Thus depletion of RBC is thought to be partly immune-mediated [15]. Infected erythrocytes bind to endothelial cells, and P. falciparum antigens known as erythrocyte membrane protein 1 (PfEMP1), inserted into the infected erythrocyte surface, mediate this interaction. It has been argued that these antigens are recognized by IgG subclasses that activate the classical complement pathway [16]. This pathway may also be triggered by binding of immune complexes or dead merozoites to the RBC surface [17]. As a result, monocytes, which have $\mathrm{C} 3 \mathrm{~b}$ and $\mathrm{C} 3 \mathrm{~b} \alpha \beta$ receptors on their surfaces, are activated to phagocytose the infected RBC. Thus, complement does not seem to kill parasites directly, but could play a role as an opsonin for neutrophils and macrophages [18]. In line with this, previous studies have shown that binding of complement factor C3d to RBC is common in childhood malaria, whereas IgG binding is rare [19].

A role for complement activation in RBC breakdown during malaria is supported by reports of positive DCT in patients with anaemia [20-23]. In addition, the balance between the beneficial immune activation functions of the complement cascade and its detrimental role in disease pathogenesis is maintained by a large number of regulatory proteins. Some of these include, complement receptor 1 (CD35), which binds $\mathrm{C} 3 \mathrm{~b}$, and decay accelerating factor (CD55) and membrane attack complex inhibitor factor (CD59), which play a role in regulating haemolysis due to deposition of immune complexes on the surface of RBC [24]. Studies have shown that, deficiencies of these membrane-bound complement-regulatory proteins on infected and uninfected erythrocytes are associated with SM [25-28]. However, these studies did not use strictly defined patient categories and, in some cases malaria diagnosis was not confirmed in the control groups. In the present study, the role of complement activation in the pathogenesis of SM was investigated in a group of Ghanaian children presenting at hospital with strictly defined manifestations of malaria, including uncomplicated malaria (UM), SA, CM, IVH and RD. In addition, the binding of complement factors and the expression of complement regulatory proteins on RBC was investigated by flow cytometry. Given the high rate of mortality associated with RD in Ghanaian children [29], and the association between SA and RD [7], the relationship between complement activation and RD was also examined.

\section{Materials and methods Study design and patient population}

Children between one and twelve years of age with severe forms of malaria as described previously [30], were consecutively recruited into an unmatched case control study in July-August, 2000 at the Emergency Unit of the Depart- 
ment of Child Health (DCH), Korle-Bu teaching Hospital, Accra, Ghana. Apparently healthy children, randomly selected from a database of children in the same age range from a nearby community, Dodowa were enrolled as control subjects (AC) $[29,30]$. Malaria transmission in the study area, a coastal savannah, is perennial with considerable seasonal variation, peaking during and immediately after the rains (May-October). Residents are estimated to receive about 20 infective bites per year and $P$. falciparum constitutes $98 \%$ of all infections [31]. The Scientific and Technical Committee of the Noguchi Memorial Institute for Medical Research and the Ethics and Protocol Review Committee of the University of Ghana Medical School, Korle Bu, Accra approved the study. All patients and control subjects were enrolled in the study only after signed, informed, parental consent was obtained.

\section{Clinical investigation and inclusion criteria}

Patients with axillary temperature $>37.5^{\circ} \mathrm{C}$ of no other obvious cause than malaria were screened for inclusion by a project physician. Clinical parameters were documented on standard written forms. Spleen enlargement was assessed by palpation and quantified as $\mathrm{cm}$ below the left costal margin along the mid-clavicular line. Patients with $P$. falciparum parasitaemia $\geq 10,000$ parasites $/ \mu \mathrm{L}$ were enrolled into the study if they fell into one of the following patient categories [29]: SA: haemoglobin (Hb) $<5$ g/ $\mathrm{dL}$, fully conscious with no episodes of severe bleeding, reported or observed convulsions; CM: Blantyre coma score $\leq 3$ and duration of coma $>60$ minutes, any $\mathrm{Hb}$ value and no record of recent severe head trauma and other cause of coma or neurological diseases; IVH: evidence of haemoglobinuria detected by the urine dipstick test (Roche Diagnostics Ltd, Great Britain) followed by microscopy as described elsewhere [21]; RD: rapid breathing plus one or more of the following: alar flare, chest recessions, use of accessory muscles for respiration, or abnormally deep breathing; $\mathrm{UM}: \mathrm{Hb}>8 \mathrm{~g} / \mathrm{dL}$, fully conscious, no other features of SM. Patients with Hb between 5 and $8 \mathrm{~g} / \mathrm{dL}$ were only included if they fell into one or more of the patient categories: IVH, CM and RD.

\section{Exclusion criteria}

Patients who were sickling positive were excluded. Other haemoglobinopathies were not taken into consideration. Patients were also excluded from the study based on evidence of other infectious disease such as typhoid or upper respiratory tract infections or any other identified cause of anaemia than malaria. Patients with a history of antimalarial treatment within 2 weeks prior to admission were excluded $[13,14]$.

\section{Management of patients}

Based on institutional practice at the time, all patients with UM were treated with a standard chloroquine regime at a total dose of $25 \mathrm{mg} / \mathrm{kg}$ body weight, given over three days. In the event of treatment failure, treatment with amodiaquine $(10 \mathrm{mg} / \mathrm{kg}$ body weight per day, as single daily doses for three days) was instituted. All patients with SM were treated with either amodiaquine syrup via nasogastric tube at the same dosage as described, or intramuscular quinine dihydrochloride $(10 \mathrm{mg} / \mathrm{kg}$ body weight, 8-hourly). Parenteral quinine was changed to syrup at the same dosage when patients regained full consciousness or after 72 hours (which ever was earlier), to complete a 7-day course. Patients with SA or RD were given humidified oxygen and children with $\mathrm{Hb}<5 \mathrm{~g} / \mathrm{dL}$ received blood transfusions [29].

\section{Blood sampling and laboratory analysis}

Immediately after admission, $5 \mathrm{ml}$ of venous blood was collected into EDTA tubes from all patients screened for inclusion. Haematological profile was determined using an 18-parameter, automatic haematology analyzer (Sysmex KX-21, Japan). Sickling test was done using the sodium metabisulphite test. Giemsa-stained thick and thin blood films were used for microscopic detection and identification of Plasmodium parasites. Parasites were counted against $300 \mathrm{WBC}$, and the value was converted into parasites per $\mu \mathrm{L}$ of peripheral blood, based on individual WBC count. Quality control (QC) was ensured by checking the autoanalyser daily and testing of $10 \%$ slides by second look. Errors were below $10 \%$ variation or disagreement and without systematic deviations.

\section{Direct Coombs' test}

DCT was done using the method described by Goka et al. [21]. RBC suspensions were washed 4 times in comparatively large volumes ( $4 \mathrm{ml}$ per wash) of $0.9 \%$ saline by centrifugation and reconstituted with saline to 5\% PCV. One drop of this suspension was mixed with two drops of poly-antiglobulin sera (DIAGAST laboratories, Cedex, France), followed by centrifugation at 1,200 rpm for 1 minute. The samples were immediately inspected macroscopically for agglutination and negative or doubtful positive/weak results were re-examined by light microscopy. The positive samples were re-tested using mono-specific antiserum against IgG and C3d. Test results were graded as +4 (complete agglutination), +3 (several large agglutinates, few cells), +2 (large agglutinates in a sea of smaller clumps and free cells), +1 (many small agglutinates) or 0 (no agglutination). Positive and negative controls were run in parallel.

\section{Flow cytometry}

Packed RBC were washed twice by centrifugation and resuspended in PBS (pH 7.2) to $2.0 \times 10^{7}$ cells $/ \mathrm{ml}$. The RBC suspension was stained with ethidium bromide (50 $\mu \mathrm{g} / \mathrm{ml}$ final concentration), followed by surface staining with FITC-conjugated antibodies in the dark [32]. The fol- 
lowing antibodies were used: Mouse IgG $_{1}$ FITC (Pharmigen International, 33814X, San Diego, CA, USA); CD35 (Pharmigen, 30961A); IgG (Becton Dickinson, San Jose, CA, USA, 345140\{5140\}); Mouse IgG Ig $_{2}$ FITC (Pharmigen, 33034X); CD55 (Pharmigen, 33571A); Mouse IgG pure (DAKO, Glostrup, Denmark, X 0931); C3b $\alpha \beta$ (Cymbus Biotechnology Ltd., Hampshire, UK, CBL 189 for $\alpha$; CBL 190 for $\beta$ ); Rabbit IgG pure (Zymed Laboratories, INC., San Franscisco, California, USA, 81245172); C3d pure (DAKO, A 0063); C3d FITC (DAKO, F 0323) and controls (Goat anti-mouse FITC (DAKO, F0479); Swine anti-rabbit FITC (DAKO, F0054). After incubation, cells were washed twice with cellwash (Becton Dickinson) by centrifugation and samples were stored at $4{ }^{\circ} \mathrm{C}$ in the dark till acquisition on a FACScan flow cytometer (Becton Dickinson, Japan). A minimum of 10,000 RBC were acquired and analysis was done by the CellQuest programme. The cut-off point was $10^{1}$ on both axes.

\section{Statistical analysis}

Statistical analysis was performed using SigmaStat software package (Jandel Scientific). Continuous variables were compared between groups using the student t-test or one way analysis of variance (ANOVA). For data that were not normally distributed and could not be normalised by logarithmic transformation a one-way ANOVA on ranks was used. Correlation between parameters was determined by Spearman rank order test. Proportions were compared using the Chi-square test, or Fisher's exact test. Variables that showed significant or near-significant differences between groups by univariate analysis or that were otherwise considered relevant for the study were entered in a conditional logistic regression analysis and in a multiple regression analysis. P-values $<0.05$ were considered significant.

\section{Results}

\section{Characteristics of the patient categories and controls}

A total of 484 parasitaemic patients were screened for enrolment of which 87 patients with distinct clinical presentations of SM were included, 36 SA, 18 IVH, 27 CM and 6 RD. Their clinical characteristics together with those of UM patients and AC are summarised in Table 1. SA patients were younger (mean age $=2.5 \mathrm{yrs}$.) than the other categories of patients and the AC group (mean age 5.7 yrs.) ( $\mathrm{p}<0.001)$. SA had the lowest mean $\mathrm{Hb}(4.1 \mathrm{~g} / \mathrm{dL})$, followed by RD $(5.5 \mathrm{~g} / \mathrm{dL})$ and IVH $(6.5 \mathrm{~g} / \mathrm{dL})$. The highest mean $\mathrm{Hb}$ was found in $\mathrm{AC}(10.9 \mathrm{~g} / \mathrm{dL})$. All the patient categories had high parasitaemia whilst $\mathrm{AC}$ had the lowest parasite density (geometric mean, $1.4 \times 10^{3}$ parasites $/ \mu \mathrm{L}$ ). The geometric mean parasite densities of SA and UM cases (63.0 and $57.3 \times 10^{3}$ parasites $/ \mu \mathrm{L}$ respectively) were significantly lower than those of the IVH, CM and RD cases $\left(98.7 \times 10^{3}, 114.9 \times 10^{3}\right.$ and $80.9 \times 10^{3}$ parasites $/ \mu \mathrm{L}$, respectively, $\mathrm{p}<0.001)$. In order to study the effect of complement activation on $\mathrm{RD}$, the data were re-analysed for all patients with SM, including those with overlapping clinical manifestations. The characteristics of these 104 children is summarised in Figure 1. Forty-six children had $\mathrm{Hb}<5 \mathrm{~g} / \mathrm{dL}, 34$ had coma score $\leq 3,22$ had haemoglobinuria and 20 had RD.

\section{Association of variables in children with severe malaria}

Of all the parameters tested, only age and spleen size showed a significant correlation with $\mathrm{Hb}$ (Table 2). Age was positively correlated with $\mathrm{Hb}(\mathrm{r}=0.379, \mathrm{p}=0.002)$, and spleen size was inversely correlated to $\mathrm{Hb}(\mathrm{r}=-0.402$, $\mathrm{p}=0.001)$.

\section{Clinical characteristics of DCT positive and negative patients and controls}

Of all the patients screened (484), 27.0\% (131) were DCT positive. Most of the sensitisation was due to $\mathrm{C} 3 \mathrm{~d}$ alone $(87.8 \%)$, with a small proportion being ascribed to IgG alone $(2.3 \%)$ or to both $(9.9 \%)$. Children below 5 years formed $84.7 \%(111 / 131)$ of the DCT positives relative to those of 5 years and older, OR $=3.8$ (95\% CI, 2.2-6.7, p $<0.001)$. There was a high prevalence of DCT positive cases in the RD (50.0\%), IVH (38.8\%) and SA (27.8\%) patients whereas UM and CM had $9.5 \%$ and $11.8 \%$ prevalence respectively. Surprisingly, $26.3 \%$ of the AC patients had positive DCT (Table 1). When overlapping cases were included in the analysis, RD patients still had the highest DCT positive rate with $(50.0 \%,(10 / 20))$, followed by IVH $(45.5 \%,(10 / 22))$; SA $(34.8 \%,(16 / 46))$ and CM $(20.6 \%$, $(7 / 34))$, Figure 1 . Of all the children with severe forms of malaria (SM, n = 104), 33 (31.6\%) were DCT positive (Table 3). There were no significant differences in age and parasitaemia between the DCT positive and the DCT negative patients of the SM ( $\mathrm{p}>0.05$, Table 3$)$, whereas the mean $\mathrm{Hb}$ was significantly lower in the DCT positive patients $(\mathrm{p}<0.001)$. Although there was a trend toward higher prevalence of a positive DCT in RD, IVH, and SA, compared with $\mathrm{CM}$, these associations were not statistically significant (Table 3 ).

\section{Relationship between DCT result and RD}

Out of 20 RD cases, $50.0 \%$ (10/20) were DCT positive compared with $27.4 \%$ (23/84) non RD cases, $\mathrm{p}=0.092$. Furthermore, the strength of the DCT result (0-4) correlated significantly with RD (standard coefficient $\beta=$ $0.304, \mathrm{p}=0.006$ ). Since children with RD appeared to be more likely to have DCT positive results compared to those without RD, the relationship between DCT result and $\mathrm{RD}$ was further investigated using multiple linear regression where the strength of the DCT result, $\mathrm{Hb}$, coma score, and age were tested for their contribution to RD. In this model, $\mathrm{Hb}(\beta=-0.341, \mathrm{p}=0.012)$ and coma score $(\beta$ $=-0.256, \mathrm{p}=0.031$, Table 4$)$ emerged as the strongest predictors of RD compared with DCT grade $(\beta=0.228, \mathrm{p}=$ 


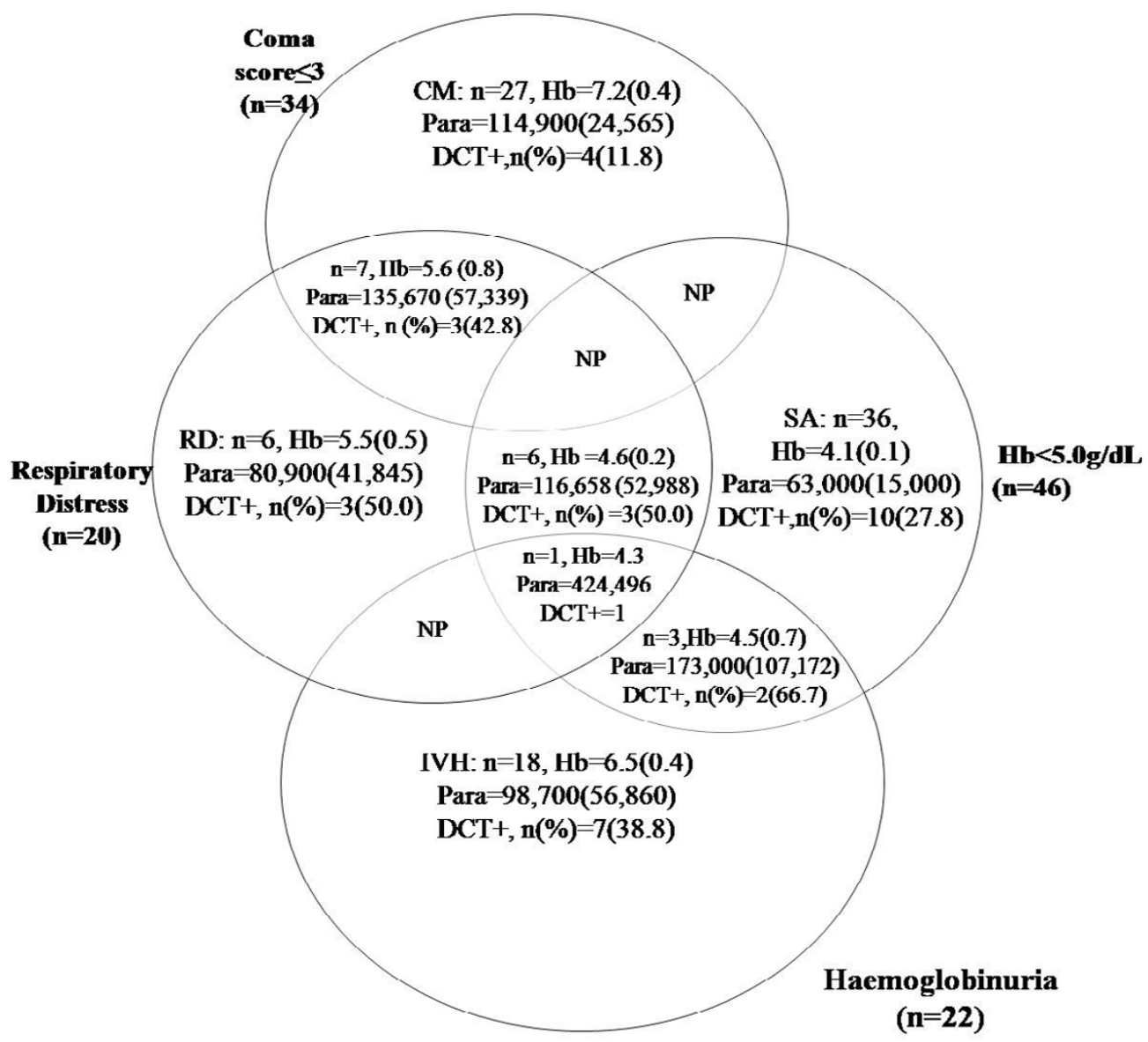

Figure I

Clinical categories of children with severe malaria. Children admitted to the paediatric ward of the Korle-Bu teaching hospital, Accra, with severe malaria (SM). Symptoms of SM included coma (score $\leq 3$ on the Blantyre coma scale), severe anaemia (SA) (haemoglobin $[\mathrm{Hb}]<5.0 \mathrm{~g} / \mathrm{dL}$ ), intravascular haemoloysis (IVH, evidence of haemoglobinuria), and respiratory distress (RD). The number of children showing the various symptoms, as well as the mean (SEM) $\mathrm{Hb}$ (in g/dL) and parasitaemia (Para, in parasites per $\mu \mathrm{L}$ ) plus prevalence of a direct Coombs' test (DCT) is shown. NP, no patient.

Table I: Demographic, clinical and laboratory characteristics of patients and healthy controls

\begin{tabular}{|c|c|c|c|c|c|c|c|}
\hline Characteristics & SA & IVH & CM & RD & UM & AC & p value \\
\hline $\mathrm{n}$ & 36 & 18 & 27 & 6 & 21 & 19 & - \\
\hline Female sex, $\%$ & 43.7 & 21.1 & 40.7 & 60.0 & 42.8 & 47.8 & - \\
\hline Mean Age, years $(95 \% \mathrm{Cl})$ & $2.5^{* *}(1.8-3.1)$ & $4.8(3.1-6.6)$ & $4.3(3.3-5.3)$ & $2.7^{* *}(2.0-5.5)$ & $5.2(3.6-6.8)$ & $5.7(4.4-7.1)$ & $<0.00 I^{b}$ \\
\hline DCT Positive, $n(\%)$ & $10 *(27.8 \%)$ & $7 *(38.8 \%)$ & $4(11.8 \%)$ & $3 * 50.0 \%$ & $2(9.5 \%)$ & $5.0 *(26.3 \%)$ & $<0.05^{\mathrm{a}}$ \\
\hline Mean $\mathrm{Hb}, \mathrm{g} / \mathrm{dL}(95 \% \mathrm{Cl})$ & $4.1(3.8-4.3)$ & $6.5(5.6-7.4)$ & $7.2(6.4-8.0)$ & $5.5(4.6-6.2)$ & $9.2(8.5-9.8)$ & $10.9(10.6-11.4)$ & - \\
\hline $\begin{array}{l}\text { Parasite density, geometric mean } \\
\text { parasites } \times 10^{3} / \mu \mathrm{L}(95 \% \mathrm{Cl})\end{array}$ & $63.0 * * * *(34.3-94.1)$ & $98.7(47.6-284.5)$ & $114.9(67.4-162.6)$ & $80.9(12.1-256.9)$ & $57.3 * * *(41.0-107.3)$ & $1.4(0-2.9)$ & $<0.00 \mathrm{I}^{\mathrm{b}}$ \\
\hline Spleen size, $\mathrm{cm}(95 \% \mathrm{Cl})$ & $2.3(1.5-3.0)$ & $0.6(0-1.6)$ & $0.7(0.1-1.4)$ & ND & $1.9(0.6-3.2)$ & ND & - \\
\hline
\end{tabular}

Non-overlapping patient groups (see text). SA, severe anaemia ( $\mathrm{Hb}<5 \mathrm{~g} / \mathrm{dL})$. IVH, intravascular haemolysis with evidence of haemoglobinuria. CM, cerebral malaria (coma score $\leq 3$ ). RD, respiratory distress. UM, uncomplicated malaria with $\mathrm{Hb}>8 \mathrm{~g} / \mathrm{dL}$. AC, healthy, asymptomatic controls. DCT, direct Coombs' test. *Significantly higher than UM and CM. ** Significantly lower than CM, UM and AC. *** Significantly lower than IVH and CM. ND, not done.

$\mathrm{a}=$ Calculated using $X^{2}$

$\mathrm{b}=$ Calculated using ANOVA 
Table 2: Correlation between variables in children with severe or uncomplicated malaria

\begin{tabular}{|c|c|c|c|c|c|c|c|c|}
\hline \multirow[b]{2}{*}{ Variable } & \multicolumn{2}{|c|}{$\mathrm{Hb}$} & \multicolumn{2}{|c|}{ Spleen } & \multicolumn{2}{|c|}{ Coma } & \multicolumn{2}{|c|}{ Log para } \\
\hline & $r$ & $p$ & $r$ & $p$ & $r$ & $p$ & $r$ & $p$ \\
\hline Age & 0.379 & 0.002 & -0.066 & 0.610 & -0.142 & 0.265 & -0.0618 & 0.630 \\
\hline $\mathrm{Hb}$ & & & -0.402 & 0.001 & -0.201 & 0.114 & -0.053 & 0.678 \\
\hline Spleen & & & & & 0.270 & 0.032 & -0.170 & 0.183 \\
\hline Coma & & & & & & & -0.208 & 0.102 \\
\hline
\end{tabular}

$\mathrm{Hb}$, haemoglobin. Spleen size, cm below left costal margin. Coma, score $\leq 3$ on the Blantyre coma scale. Para, parasite (per $\mu \mathrm{L}$ ). Patients analysed here are all the SM and UM cases $(n=125)$. Asymptomatic controls $(A C)$ are not included.

$0.061)$ and age $(\beta=0.208$ and $p=0.820)$. These results suggest that the association between RD and DCT may be related to the role of DCT in precipitating anaemia.

\section{Relationship between opsonins (C3d and $\mathrm{C} 3 \mathrm{~b} \alpha \beta$ ) and complement regulatory proteins (CD35 and CD55) in different patient categories}

The association between the DCT method and flow cytometry was confirmed by a positive correlation between DCT grade and MFI after surface staining of RBC with anti-C3d ( $\mathrm{r}=0.53, \mathrm{p}<0.001$, Figure 2$)$. In order to study the influence of complement regulatory proteins on clinical outcome, binding of $\mathrm{C} 3 \mathrm{~d}$ and $\mathrm{C} 3 \mathrm{~b} \alpha \beta$ and expression of CD35 and CD55 on the RBC surface were measured by flow cytometry in a subset of the patients (Table 5 ). As shown in Table 5, there were no differences in any of the tested parameters between the main clinical groups $(p>0.7)$. The binding of C3b $\alpha \beta$ correlated significantly with CD35 and CD55 ( $<<0.001)$ in children with SM, Figure 3. There was no correlation between C3d and either CD35 or CD55 ( $>$ > 0.05, data not shown).

\section{Discussion}

Results from the present study show that infection with $P$. falciparum parasites stimulates complement activation, consistent with previous studies [21-23,33]. The complement activation was associated with reduced Hb-levels
$[21,22,24]$. A central molecule in this association appears to be $\mathrm{C} 3 \mathrm{~d}$ that can opsonise the RBC for erythrophagocytosis. To a large extent, the erythrophagocytosis is mediated by macrophages, as indicated by increased levels of neopterin $[29,30,34]$, which is a marker of macrophage activation [35]. The combination of activated macrophages and RBC opsonised by complement after activation will lead to increased erythrophagocytosis and decreased $\mathrm{Hb}$ as demonstrated in other studies $[21,36]$. This was reflected in an inverse correlation between spleen size and $\mathrm{Hb}$ and a trend toward larger spleen size in DCT positive than in DCT negative patients. Thus, phagocytosis of iRBC caused by macrophages in the spleen, enhanced by the opsonisation of RBC by C3d, may be one of the mechanisms by which $\mathrm{Hb}$ drops due to $P$. falciparum infection. However, a prospective study comparing DCT positive and negative patients in relation to drop in Hb after initiation of treatment would be relevant to confirm a causal relationship.

Complement activation could additionally contribute to malarial anaemia by direct lysis of infected RBC [5]. However, both this and a previous study [21] only showed a weak and insignificant association between DCT results and haemoglobinuria. Other factors apart from complement that may trigger IVH in malaria are drugs such as chloroquine $[13,14]$, genetic factors $[10,37]$ and autoim-

Table 3: Clinical characteristics of all children with severe malaria grouped by DCT results

\begin{tabular}{|c|c|c|c|}
\hline Characteristics & DCT positive & DCT negative & $P$ value \\
\hline n (\%) & $33(31.6 \%)$ & $71(68.2 \%)$ & - \\
\hline Age, years & $3.3(2.5-4.0)$ & $4.0(3.4-4.6)$ & $0.11^{\mathrm{b}}$ \\
\hline $\mathrm{Hb}, \mathrm{g} / \mathrm{dL}$ & $5.0(4.3-5.6)$ & $6.6(6.1-7.1)$ & $<0.00 I^{b}$ \\
\hline Parasite density, $\times 10^{3} / \mu \mathrm{L}$ & $125.6(81.5-169.7)$ & 139.7 (107.6-|7|.8) & $0.33^{\mathrm{b}}$ \\
\hline Mean spleen size, $\mathrm{cm}$ & $2.1(1.1-3.1)$ & $1.2(0.6-1.8)$ & $0.09 b$ \\
\hline SA, n (\%) & $16(48.5 \%)$ & $30(42.3 \%)$ & $0.70^{\mathrm{a}}$ \\
\hline CM, n (\%) & 7 (21.2\%) & 27 (38.0\%) & $0.15^{\mathrm{a}}$ \\
\hline Haemoglobinuria, n (\%) & $10(30.3 \%)$ & $12(16.9 \%)$ & $0.19 a$ \\
\hline Mortality, n (\%) & $4(12.1 \%)$ & $15(21.1 \%)$ & $0.40^{\mathrm{a}}$ \\
\hline
\end{tabular}

Data are mean ( $95 \%$ confidence interval) unless otherwise indicated. Patients include all patients in Figure I. Thus, the same patient can appear in several categories.

$\mathrm{a}=$ Calculated using $X^{2}$ or Fischer's exact test

$\mathrm{b}=$ Calculated using, student t-test 
Table 4: Multiple regression analysis of variables predicting respiratory distress

\begin{tabular}{lcc}
\hline Characteristics & Standard coefficient $(\beta)$ & P-value \\
\hline Age (years) & 0.208 & 0.820 \\
Coma score & -0.256 & 0.031 \\
Hb (g/dL) & -0.341 & 0.012 \\
DCT grade (0-4) & 0.228 & 0.061 \\
\hline
\end{tabular}

NB: Patients analysed here are all the SM and UM cases $(n=125)$. AC were not included.

munity [38]. Apart from excluding sickle cell genes, other factors were not controlled for in this study. However, the lack of association between DCT and IVH suggests that the main contribution of complement activation to the pathogenesis of malarial anaemia is opsonisation for erythrophagocytosis. The surprisingly high prevalence of DCT positives in the AC group indicates that a number of apparently healthy children may have an activated complement system. In a related study [39], it was observed that asymptomatic $P$. falciparum infection resulted in immune activation and anaemia in semi-immune children. The present study suggests that complement activation could contribute to the low $\mathrm{Hb}$ in the semi-immune children.

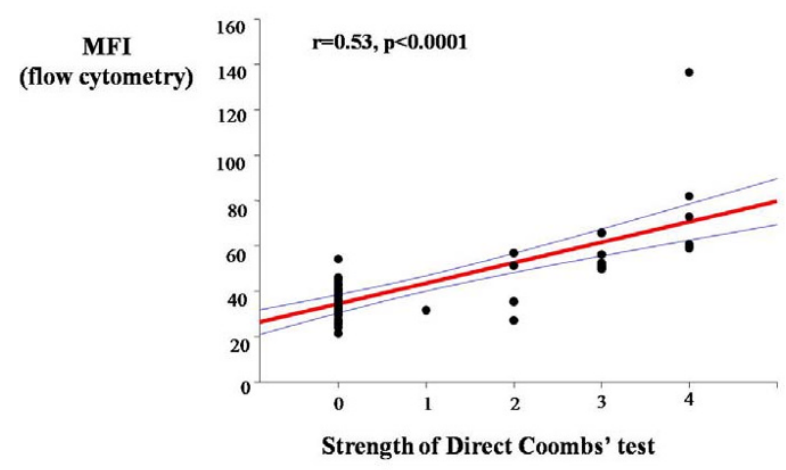

\section{Figure 2}

DCT results compared with flow cytometry using anti-C3d. RBC suspensions from 30 DCT positive and negative SM patients were stained with ethidium bromide and monoclonal antibodies to detect surface-bound C3d. Association between DCT results and flow cytometry results for C3d are shown by scatter plots with regression line. MFI, mean fluorescence intensity. DCT was graded as accordingly as +4 (complete agglutination), +3 (several large agglutinates, few cells), +2 (large agglutinates in a sea of smaller clumps and free cells), +1 (many small agglutinates), 0 (no sign of agglutination).

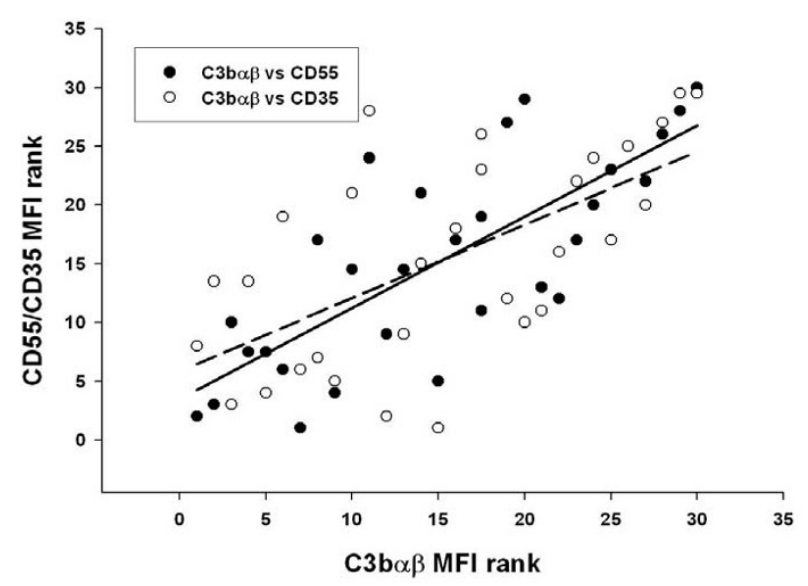

Figure 3

Association of CD55 and CD35 with $C 3 \alpha \beta$ in children with severe malaria. Correlation between $C 3 b \alpha \beta$ and complement regulatory proteins (CD35 (complement receptor type I) and CD55 (decay accelerating factor)) measured by flow cytometry on surfaces of RBC from 30 children with SM. Solid line: $C 3 b \alpha \beta$ vs $C D 55, r=0.777, p<0.001$; dotted regression line: $C 3 b \alpha \beta$ vs CD $35, r=0.624, p<0.001$. MFI, mean fluorescence intensity.

In the present study the DCT [40] was used alongside flow cytometry to determine the relationship between the levels of complement fragments $(\mathrm{C} 3 \mathrm{~b} \alpha \beta)$ and regulatory proteins (CD35 and CD 55). Other investigators have shown that activation and levels of regulatory proteins on surfaces of RBC are related to RBC loss in malaria $[25,28]$. In contrast, the present study did not find any relationship between anaemia and CD35 and CD55 levels. Unlike the current study, the previous studies did not use strictly defined patient categories and, in some cases malaria diagnosis was not confirmed. However, the discrepancy could also be due to differences in responses to $P$. falciparum of children from distinct geographical locations or exposed to varying levels of malaria transmission. There is a need to perform additional investigations of the role of complement regulatory proteins in the pathogenesis of malaria anaemia. The correlation between C3 fragment deposition and CD35 and CD55 levels reported here confirms results from previous studies [41], and suggests an adequate role of CD55 in regulating the extent of haemolysis in the studies patients.

Increased levels of inflammatory mediators have been shown to play a role in RD [29]. High levels of complement factors being reported here may implicate a synergistic role of these complement factors and inflammatory mediators in causing the RD due to $P$. falciparum infection. Such a synergistic interaction has been shown to take 
Table 5: MFI levels of complement factors and regulatory proteins by patient categories

\begin{tabular}{|c|c|c|c|c|c|c|}
\hline \multirow{2}{*}{$\begin{array}{l}\text { Complement } \\
\text { factors }\end{array}$} & \multicolumn{6}{|c|}{ Patient Categories and Controls } \\
\hline & $\mathrm{SA}, \mathrm{n}=1 \mathrm{I}$ & $\mathrm{IVH}, \mathrm{n}=8$ & $C M, n=11$ & $\mathrm{UM}, \mathrm{n}=10$ & $A C, n=11$ & $P$ value \\
\hline CD35 & $2.10(1.6-2.6)$ & $2.09(1.4-2.7)$ & $2.08(1.7-2.5)$ & $1.85(1.6-2.1)$ & $1.97(1.7-2.2)$ & 0.88 \\
\hline CD55 & $2.05(1.5-2.5)$ & $1.76(1.4-2.1)$ & $1.94(1.7-2.2)$ & $1.85(1.7-2.0)$ & $1.98(1.7-2.3)$ & 0.81 \\
\hline $\mathrm{C} 3 \mathrm{~b} \alpha \beta$ & $2.90(0.7-5.1)$ & $2.74(1.1-4.5)$ & $1.94(1.1-2.8)$ & $2.11(1.4-2.8)$ & $3.30(1.2-5.4)$ & 0.76 \\
\hline
\end{tabular}

Data are represented as means (95\% confidence intervals). CD35, Complement receptor type I. CD55, Decay accelerating factor. C3b $\alpha \beta$, complement fragment from breakdown of $\mathrm{C} 3 \mathrm{~b}$.

$\mathrm{a}=$ Calculated using one-way ANOVA.

place during cardiac surgery with cardiopulmonary bypass (CBP) [42]. Similarly, in addition to complement activation during severe malaria infection, there is an imbalance between pro- and anti-inflammatory cytokines. Thus in children with SA complicated by RD, institution of effective treatment during the early phase of infection appears to be critical to survival $[3,43]$. The application of simple clinical and laboratory guidelines identifying children likely to develop SM and thus most in need for rapid interventions may thus improve survival and reduce unnecessary use of blood transfusion [3]. This study demonstrates that DCT can be used as a simple and reliable method of measuring complement activation in children with acute malaria and may be used to predict progression of UM to SA-RD and SA+RD. Prospective studies are needed to validate this diagnostic approach.

\section{Conclusion}

The data presented here, supports a role for complementmediated removal of RBC through erythrophagocytosis in the pathogenesis of malarial anaemia. In contrast to previous studies there was no relationship between the severity of anaemia and levels of complement receptor 1 or decay accelerating factor. Complement activation could also be involved in the pathogenesis of RD but larger studies are needed to confirm this finding. In addition the study demonstrates that DCT might be used as a simple method of predicting development of complications but this need to be studied prospectively in subsequent investigations.

\section{Competing interests}

The author(s) declare that they have no competing interests.

\section{Authors' contributions}

GKH designed the study, carried out laboratory work, data analyses and interpretation and drafted the manuscript. BQG and GOA assisted with design of study, selection, clinical examination and management of patients, as well as revision of manuscript for intellectual content. MMA and EO assisted with Coombs' test and data analysis. $\mathrm{KH}$ was involved with data analysis and extensive revision of manuscript for intellectual content. JKAT, DD and MFO designed the flow cytometry with GKH, acquired and analyzed the data. GAA was involved in data analyses, and preparation and revision of manuscript. JALK and BDA were involved in the design of experiment, data analysis and revision of manuscript for intellectual content.

\section{Acknowledgements}

Children and their guardian/parents are thanked for participating in this study. Messrs John Arko-Mensah and William Vanderpuije are thanked for technical assistance. This study received financial support from United Nations Development Programme/World Bank/World Health Organization Special Programme for Research and Training in Tropical Diseases (TDR) (Multilateral Initiative on Malaria/TDR grant 980037); Programme for Enhancement of Research Capacity in Developing Countries, Danish International Development Assistance (DANIDA).

\section{References}

I. Marsh K, Foster D, Waruiru C, Mwangi I, Winstanley M, Marsh V, Newton C, Winstanley P, Warn P, Peshu N, Pasvol G, Robert SR: Indicators of life-threatening malaria in African children. $N$ Engl J Med 1 995, 332: I 399-404.

2. English M, Sauerwein R, Waruiru C, Mosoboi M, Obiero J: Acidosis in severe childhood malaria. QJMed 1997, 90:263-270.

3. English M, Ahmed M, Ngando C, Berkley J, Ross A: Blood transfusion for severe anaemia in children in a Kenyan hospital. Lancet 2002, 359:494-495.

4. Devakul K, Harinasuta T, Kanakorin K: Erythrocyte destruction in Plasmodium falciparum: an investigation of intravascular haemolysis. Ann Trop Med Parasitol 1969, 63:317-325.

5. O'Donnell A, Weatheral DJ, Taylor AM, Reeder JC, Allen SJ: Muscle cell injury, haemolysis and dark urine in children with falciparum malaria in Papua New Guinea. Trans R Soc Trop Med Hyg 2006, 100:817-825.

6. Breman GJ, Martins S, Alilio MA: Conquering the intolerable burden of malaria. Am J Trop Hyg 2004, 7 I (Suppl 2): I- I 5.

7. Oduro AR, Koram KA, Rogers W, Atuguba F, Ansah P, Anyorigiya T, Ansah A, Anto F, Mensah N, Hodgson A, Nkrumah F: Severe falciparum malaria in young children of the Kassena-Nankana district in northern Ghana. Mal J 2007, 6:96.

8. Morch K, Ferugho SL, Ormaasen V, Bruun JN, Tidsk : Severe falciparum malaria treated with exchange transfusion. Tidssk Nor Laegeferon 2002, I22:999-100I.

9. Ekvall H, Arese P, Turrini F, Ayi K, Mannu F, Premji Z, Bjorkman A: Acute haemolysis in childhood falciparum malaria. Trans Soc Trop Med Hyg 200I, 95:6II-6I7.

10. Sarkar S, Prakash D, Marwaha RK, Garewal G, Kumar L, Singhi S, Walia BN: Acute intravascular haemolysis in glucose-6-phosphate dehydrogenase deficiency. Ann Trop Paediat 1993, 13:391-394. 
II. Lau HK, Li CH, Lee AC: Acute massive haemolysis in children with glucose-6-phosphate dehydrogenase deficiency. Hong Kong Med J 2006, I 2: |49-151.

12. WHO Working Group: Glucose-6-phosphate dehydrogenase deficiency. Bull World Health Organ 1989, 67:601-61I.

13. Choudhry VP, Madan N, Food SK, Ghai OP: Chloroquine induced haemolysis and acute renal failure in subjects with G6PD deficiency. Trop Geogr Med 1978, 30:331-335.

14. Choudhry VP, Ghafry A, Zaher M, Qureshi MA, Fazel I, Ghani R: Drug-induced haemolysis and renal failure in children with G6PD in Afghanistan. Ann Trop Paediatric 1990, 10:335-338.

15. Price RN, Simpson JA, Nosten F, Luxemburger C, Hkirjaroen L, ter Kuile F, Chongsuphajaisidhi T, White NJ: Factors contributing to anemia after uncomplicated malaria. Am J Trop Med Hyg 200I, 65:614-622.

16. Roestenberg M, McCall M, Mollness TE, van Deuren M, Sprong T, Klasen I, Hermsen CC, Sauerwein RW, van der Ven A: Complement activation in experimental human malaria infection. Trans Roy Soc Trop Med Hyg 2007. doi: 0.1016/j.trstmh.2007.02.023

17. Perlmann P, Perlmann H, Flyg BW, Hagstedt M, Elghazali G, Worku S: Immunoglobulin E, a pathogenic factor in Plasmodium falciparum malaria. Inf Immunol 1997, 65: I 16-121.

18. Salmon D, Vilde JL, Andrieu B, Simonovic R, Lebras J: Role of immune serum and complement in stimulation of the metabolic burst of human neutrophils by Plasmodium falciparum. Inf Immunol 1986, 5 I:80I-806.

19. Abdalla $\mathrm{SH}$ : Red cell associated IgG in patients suffering from Plasmodium malaria. Br J Haemtol 1986, 62:13-19.

20. Zuckerman A: Recent studies in Malaria anaemia. Mil Med I966, |31:1201-1216.

21. Goka BQ, Kwarko H, Kurtzhals JAL, Gyan B, Ofori-Adjei E, Ohene $\mathrm{SA}$, Hviid L, Akanmori BD, Neequaye J: Complement binding to erythrocytes is associated with macrophage activation and reduced haemoglobin in Plasmodium falciparum malaria. Trans Soc Trop Med Hyg 200I, 95:545-549.

22. Facer C, Bray RS, Brown J: Direct Coombs antiglobulin reaction in Gambian children with Plasmodium falciparum malaria. I. Incidence and class specificity. Clin Exp Immunol 1979, 35:119-127.

23. Abdalla $\mathrm{SH}$, Weatherall $\mathrm{D}$ : The anaemia of Plasmodium falciparum malaria. Brit Med Bulletin 1982, 38:|47-I5I.

24. Waitumbi JN, Opollo MO, Muga RO, Misore AO, Stoute JA: Red cell surface changes and erythrophagocytosis in children with severe Plasmodium falciparum anaemia. Blood 2000, 95: $148|-| 486$

25. Stoute JA, Odindo AO, Owuor BO, Mibei EK, Opollo MO, Waitumbi JN: Loss of Red Blood Cell-Complement Regulatory Proteins and Increased levels of circulating Immune Complexes Are Associated with Severe Malaria Anaemia. J Inf Dis 2003, I87:522-525.

26. Stoute JA: Complement-regulatory proteins in severe malaria: too little or too much of a good thing. Trends Parasitol 2005, 21:2 18-223.

27. Stoute JA, Odindo AO, Owuor BO, Mibei EK, Opollo MO, Waitumbi $\mathrm{N}$ : Loss of red cell-complement regulatory proteins and increased levels of circulating immune complexes are associated with severe malarial anaemia. J Infect Dis 2003, 187:522-525.

28. Waitumbi JN, Donvito B, Kisserli A, Cohan JH, Stoute JA: Agerelated changes in red blood cell complement regulatory proteins and susceptibility to severe malaria. J infect Dis 2004, 190: II83-1191.

29. Awandare GA, Goka B, Boeuf P, Tetteh JKA, Kurtzhals JAL, Behr C, Akanmori BD: Increased levels of inflammatory Mediators in children with severe Plasmodium falciparum malaria with respiratory distress. $J$ Inf Dis 2006, 194:1438-46.

30. Kurtzhals JA, Adabayeri V, Goka BQ, Akanmori BD, Oliver-Commey JOO, Nkrumah FK, Behr C, Hviid L: Low plasma concentrations of interleukin- 10 in severe malaria anaemia compared with cerebral and uncomplicated malaria. Lancet 1998 35 I: $1768-1772$.

31. Afari EA, Appau M, Dunyo S, Baffoe-Wilmot A, Nkrumah FK: Malaria infection, morbidity and transmission in two ecological zones in southern Ghana. Afr J Health Sci 1995, 2:312-316.

32. Immunoflourescent Staining for Flow Cytometry [http:// www.ebioscience.com/ebioscience/appls/FCS.htm]
33. Wenisch C, Spitzaner S, Florris-Linau K, Rumpold H, Vanaphan S, Parschalk B, Graniger W, Looareesuwan S: Complement activation in severe Plasmodium falciparum. Clin Immuno Immunolpathol 1997, 85:166-I7I.

34. Akanmori BD, Kurtzhals JA, Goka BQ, Adabayeri V, Ofori MF, Nkrumah FK, Behr C. Hviid L: Distinct patterns of cytokine regulation in discrete clinical forms of Plasmodium falciparum malaria. Eur Cytokine Netw 2000, I I:I I3-I I8.

35. Wachter H, Fuchs D, Hausen A, Reibnegger G, Werenr ER: Neopterin as marker for activation of cellular immunity:immunologic basis and clinical application. Adv Clin Chem 1989, 27:8I-|4|.

36. Turrini F, Ginsberg H, Bussolino F, Pescarmona GP, Serra MV, Arese P: Phagocytosis of Plasmodium falciparum-infected human red cells by human ertythrocytes: involvement of immune and non-immune determinants and dependence on parasite development stage. Blood 1992, 80:801-808.

37. Chau TN, Lai ST, Lai JY, Yuen : Haemolysis complicating acute viral hepatitis in patients with normal or deficient glucose-6phosphate dehydrogenase activity. Scan J Infect Dis 1997, 29:55I-553.

38. Dhaliwal G, Cornett PA, Tierney LM Jr: Haemolytic anaemia. Am Fam Physician 2004, 69:2599-2606.

39. Kurtzhals JA, Addae MM, Akanmori BD, Dunyo S, Koram KA, Appawu MA, Nkrumah FK, Hviid L: Anaemia caused by asymptomatic Plasmodium falciparum infection in semi-immune African school children. Trans Soc Trop Med Hyg 1999, 93:623-627.

40. Coombs RRA, Mourant AE, Race RR: Detection of weak and incomplete Rh agglutinins. Lancet 1945:15-16.

41. Pawluczkowycz AW, Lindorfer MA, Waitumbi NJ, Taylor RP: Hematin promotes complement alternative pathway-mediated deposition of $\mathrm{C} 3$ activation fragments on human erythrocytes: potential implications for the pathogenesis of anaemia in malaria. J Immunol 2007, I 79:5543-5552.

42. Risner I, Ueland T, Lundbland R, Mollnes TE, Baksaas ST, Aukrust P, Svennevig JL: Changes in the cytokine network and complement parameters during openheart surgery. Interact Cardiovasc Thorac Surg 2003, 2:19-24.

43. Bojang KA, Van Hensbroek MB, Palmer A, Banya WA, Jaffar S, Greenwood BM: Predictors of mortality in Gambian children with severe malaria anaemia. Ann Trop Paediatr 1997, 17:355-359.

Publish with Biomed Central and every scientist can read your work free of charge

"BioMed Central will be the most significant development for disseminating the results of biomedical research in our lifetime. "

Sir Paul Nurse, Cancer Research UK

Your research papers will be:

- available free of charge to the entire biomedical community

- peer reviewed and published immediately upon acceptance

- cited in PubMed and archived on PubMed Central

- yours - you keep the copyright
BiolMedcentral 